\title{
Erratum to: Metagenomic Analysis of the Microbial Community in the Underground Coal Fire Area (Kemerovo Region, Russia) Revealed Predominance of Thermophilic Members of the Phyla Deinococcus-Thermus, Aquificae, and Firmicutes
}

\author{
V. V. Kadnikov ${ }^{a, *}$, A. V. Mardanov ${ }^{a}$, A. V. Beletsky ${ }^{a}$, O. V. Karnachuk ${ }^{b}$, and N. V. Ravin ${ }^{a}$ \\ ${ }^{a}$ Institute of Bioengineering, Research Center of Biotechnology, Russian Academy of Sciences, Moscow, 119071 Russia \\ ${ }^{b}$ Laboratory of Biochemistry and Molecular Biology, Tomsk State University, Tomsk, 634050 Russia \\ *e-mail:vkadnikov@bk.ru \\ Received October 28, 2021; revised October 28, 2021; accepted October 28, 2021
}

DOI: $10.1134 / \mathrm{S} 0026261722120025$

The article "Metagenomic Analysis of the Microbial Community in the Underground Coal Fire Area (Kemerovo Region, Russia) Revealed Predominance of Thermophilic Members of the Phyla DeinococcusThermus, Aquificae, and Firmicutes", written by V. V. Kadnikov, A. V. Mardanov, A. V. Beletsky, O. V. Karnachuk, and N. V. Ravin, was originally published electronically in Springer-Link on 4 October 2021 without Open Access. After publication in volume 90 , issue 5, pages 578-587 the authors decided to make the article an Open Access publication. Therefore, the copyright of the article has been changed to (C)
The Author(s) 2021 and the article is forthwith distributed under the terms of a Creative Commons Attribution 4.0 International License (http://creativecommons.org/licenses/by/4.0/, CC BY), which permits use, duplication, adaptation, distribution and reproduction of a work in any medium or format, as long as you cite the original author(s) and publication source, provide a link to the Creative Commons license, and indicate if changes were made.

The original article can be found online at https://doi.org/10.1134/S0026261721050088 